\title{
Articulação público-privada na atenção ambulatorial de média e alta complexidade do SUS: atuação da Secretaria de Estado de Saúde de Mato Grosso
}

\section{I ${ }^{1}$ Cátia Maria Costa Romano, ${ }^{2}$ João Henrique Gurtler Scatena, ${ }^{3}$ Ruth Terezinha Kehrig I}

Resumo: A ancestralidade da relação público-privada na saúde remonta à criação e ao desenvolvimento da previdência social. No SUS, tal relação se manteve e tem ganhado força e estabilidade, principalmente nos níveis de atenção onde há possibilidade de lucro. Este estudo, de base qualitativa e foco na Secretaria de Estado de Saúde de Mato Grosso (SES), visa explorar, nessa esfera de gestão, a articulação público-privada no âmbito da assistência ambulatorial de média e alta complexidade. A coleta de dados contemplou documentos e entrevistas com técnicos daquela instância, material empírico explorado mediante análise de conteúdo. Os resultados mostraram que: o estado credencia/habilita ou contrata serviços de assistência ambulatorial de média e alta complexidade segundo a lógica da oferta privada; a gestão das açōes de saúde é deficiente; a atuação das Comissões Intergestores Regionais é passiva; e as Organizaçôes Sociais de Saúde têm processo diferenciado de avaliação e controle e recebem valores bem superiores aos da tabela SUS, não atendendo protocolos e parâmetros instituídos. Não há evidências de que a atuação atual da SES vá reverter o favorecimento do setor privado nesse nível de atenção.

> Palavras-chave: Sistema Único de Saúde; serviços de saúde; assistência ambulatorial.

\author{
1 Escola de Enfermagem da \\ Universidade Federal da Bahia. \\ Salvador-BA, Brasil. Endereço \\ eletrônico: catia.romano4@ \\ gmail.com; romano@ufba.br \\ ${ }^{2}$ Instituto de Saúde Coletiva, \\ Universidade Federal de \\ Mato Grosso. Cuiabá-MT, \\ Brasil. Endereços eletrônicos: \\ jscatena@ufmt.br; jscatena@ \\ terra.com.br \\ ${ }^{3}$ Instituto de Saúde Coletiva, \\ Universidade Federal de Mato \\ Grosso. Cuiabá-MT, Brasil. \\ Endereço eletrônico: ruth. \\ kehrig@gmail.com
}

Recebido em: 27/07/2014 Aprovado em: 28/06/2015 
$\mathrm{Na}$ Constituição Federal (CF) de 1988 (BRASIL, 1988), o aparelho jurídicopolítico do Estado permitiu a continuidade da participação do setor privado na complementação de serviços de saúde no Sistema Único de Saúde (SUS). Assim, desde seu nascimento, o SUS vem legalmente atrelado à participação do setor privado, mantendo o que, historicamente, vinha ocorrendo na assistência previdenciária no Brasil, ancorada na compra de serviços privados. Na implementação do sistema previdenciário, a participação privada na saúde ganhou maior institucionalidade no governo militar, com a unificação dos institutos pelo INPS (1966) e a posterior criação do INAMPS (1974), propiciando a reprodução de grande parte do setor privado de prestação de serviços.

$\mathrm{Na}$ tentativa de integrar os serviços de saúde privados e filantrópicos no contexto da descentralização do SUS, o Estado delegou aos municípios e aos estados a função de estabelecer contratos e convênios com esses prestadores, acompanhando o seu desempenho (CAMPOS, 2008).

Paim (2009) salienta que o setor privado, aparentemente paralelo ao SUS, possui várias "conexões" com o setor público, tornando o sistema de serviços de saúde no Brasil complexo e segmentado, com distintos padrōes de acesso, qualidade e integralidade da atenção, reforçando as desigualdades na oferta de serviços à população e no acesso a esses serviços.

Ao regulamentar o SUS, a Lei no 8.080 (BRASIL, 1990) admite à iniciativa privada sua participação nesse sistema em caráter complementar, mediante contrato regido pelo direito público. Outras leis, como a que viabilizou as organizações sociais - Lei no 9.637/98 (BRASIL, 1998) - e a Portaria no 3.410/ GM (BRASIL, 2013), que trata do processo de contratualização de serviços privados, apontam a tendência do aparelho jurídico-político do Estado na indução da ampliação do setor privado no SUS (ROMANO; SCATENA, 2014).

São grandes as dificuldades de criação e manutenção de um modelo de gestão pública no SUS que consiga assegurar a prestação dos serviços à população, sem depender da complementação do setor privado. Assim como no passado, interesses capitalistas de grupos hegemônicos mantêm essa situação, que lhes é interessante, pois lhes permite a participação num setor com alta lucratividade (BRAGA; PAULA, 1981). Tais interesses são consolidados mediante espaços 
existentes na própria legislação estatal, garantindo que a atuação privada se infiltre no setor público de forma perversa, segundo "arranjos" em modelos de gestão público-privada com pouca transparência, baixa resolutividade e pouco respeito ao princípio da equidade.

Autores como Bahia (2008), Menicucci (2010) e Cohn (2011) salientam que não existem estudos suficientes sobre o tema da privatização da rede assistencial do SUS e das relações entre os setores público e privado no Brasil, dificultando a compreensão dos intrincados liames que articulam esses dois sistemas.

Diante do exposto, pretende-se, nesse estudo, analisar a atuação da Secretaria Estadual de Saúde (SES) de MT na articulação público-privada da atenção ambulatorial de média e alta complexidade do SUS, buscando: compreender os mecanismos utilizados pela SES-MT no credenciamento/ habilitação e contratualização dos serviços ambulatoriais de média e alta complexidade do setor privado/filantrópico; entender como se processa o controle e a avaliação desses serviços pela SES; discutir os procedimentos de pagamento dos serviços ambulatoriais de média e alta complexidade do setor privado/filantrópico pela SES.

\section{Método}

Trata-se de uma pesquisa de natureza qualitativa e exploratória, desenvolvida no estado de Mato Grosso, tendo a SES como lócus de estudo. Nesse estado, a maioria dos municípios é de pequeno porte, com menos de 20 mil habitantes; há grande dispersão entre eles, amplas distâncias e outras barreiras geográficas, fatores que dificultam o acesso e, consequentemente, a integralidade da atenção em saúde (GUIMARÃES, 2012).

Os dados coletados são oriundos de fontes secundárias (documentos, portarias, resoluções, normas etc.) e primárias (seis entrevistas semiestruturadas com técnicos de setores estratégicos da SES). A análise de conteúdo (BARDIN, 1977) orientou a exploração e análise dos dados, com base em matriz construída para este trabalho (Quadro 1). O estudo foi aprovado pelo Comitê de Ética do HUJM (Protocolo no 681/CEP-HUJM/09 e Ofício no 079/CEP-HUJM/2011), cumprindo todas as normas éticas estabelecidas, inclusive a assinatura de Termo de Consentimento Livre e Esclarecido. As entrevistas foram codificadas com siglas aleatórias, no sentido de manter o sigilo ético. 
Quadiro 1. Matriz de Coleta, Processamento e Análise dos Dados

\begin{tabular}{|c|c|c|c|c|}
\hline \multirow[t]{2}{*}{ Dimensão } & \multirow[t]{2}{*}{ Subdimensão } & \multirow[t]{2}{*}{ Categorias } & \multicolumn{2}{|c|}{ Fonte de Evidência } \\
\hline & & & $\underline{\text { Documentos }}$ & $\underline{\text { Entrevistas }}$ \\
\hline \multirow{3}{*}{ 1.Macrorregulação } & \multirow{3}{*}{$\begin{array}{l}\text { Regulação da } \\
\text { atenção à saúde: } \\
\text { mecanismos } \\
\text { estratégicos de } \\
\text { gestão na SES- } \\
\text { MT }\end{array}$} & $\begin{array}{l}\text { A. Credenciamento/ } \\
\text { Habilitação e } \\
\text { Contratualização do } \\
\text { Setor Privado }\end{array}$ & SES; TCU & $\begin{array}{l}\text { Técnicos } \\
\text { da SES }\end{array}$ \\
\hline & & $\begin{array}{l}\text { B. Controle e } \\
\text { Avaliação }\end{array}$ & SES; & $\begin{array}{l}\text { Técnicos } \\
\text { da SES }\end{array}$ \\
\hline & & $\begin{array}{l}\text { C. Pagamento } \\
\text { do setor Privado/ } \\
\text { Filantrópico e OSS }\end{array}$ & SES; & $\begin{array}{l}\text { Técnicos } \\
\text { da SES }\end{array}$ \\
\hline
\end{tabular}

\section{Resultados e Discussão}

Da base empírica levantada, são aqui apresentadas as categorias analíticas: credenciamento/habilitação e contratualização com o setor privado; controle e avaliação da SES; pagamento do setor privado/filantrópico e Organizações Sociais de Saúde.

\section{Credenciamento/habilitação e contratualização com o setor privado} Em Mato Grosso, o credenciamento/habilitação ainda segue as regras definidas pelo Pacto pela Saúde (BRASIL, 2006b). A SES está iniciando internamente o trabalho de discussão e compreensão do processo definido pelo Decreto ${ }^{\circ}$ 7.508/2011, que regulamenta a Lei 8080/90 (BRASIL, 2011), entendendo que esse trabalho seria finalizado com um Contrato Organizativo da Ação Pública (COAP), ainda não assinado pelo estado. Somente a partir dessa compreensão é que a SES fará um trabalho com as regiôes de saúde na perspectiva de sua assinatura.

[...] então assim, nós ainda aqui [na SES], começamos a trabalhar internamente, sabe? Começando a dividir tarefas, entendendo ainda o processo [Decreto $\mathrm{n}^{\circ} 7508$ ] pra poder sair pras regiōes... (E4)

Nesse estado, os serviços ambulatoriais de média e alta complexidade do SUS têm tratamento distinto; os primeiros são credenciados pelo gestor municipal ou estadual, dependendo do tipo de sistema de gestão, enquanto que os de alta complexidade são habilitados pelo gestor federal. 
Romano e Scatena (2014) constataram que em MT há maior concentração

de estabelecimentos ambulatoriais de média e alta complexidade na capital do estado, considerada referência estadual e regional, e também que no estado o setor privado/filantrópico é o principal detentor da oferta desses serviços no SUS, da produção e dos recursos financeiros relacionados a eles. Por outro lado, os instrumentos de planejamento estão desatualizados, como ocorre com o Plano Diretor de Regionalização (PDR) e a Programação Integrada e Pactuada (PPI), assim como os dados do Cadastro Nacional de Estabelecimentos de SaúdeCNES (BRASIL, 2009). Assim, possivelmente, é a oferta desses serviços que induziria os credenciamentos/habilitações na assistência ambulatorial de média e, sobretudo, de alta complexidade, prevalecendo o setor privado.

[Se]... o prestador é favorável ao credenciamento, então ele oferta seu serviço..., manifesta a aceitação do preço SUS e das condições SUS [...]. Aí ele já encaminha o ofício solicitando o credenciamento... (E3).

Mas, assim, a gente vê que, em muitas situações, ainda são credenciados pela solicitação do próprio prestador... (E1).

Se a provisão da assistência ambulatorial, principalmente de alta complexidade, segue a lógica da oferta dos serviços, geralmente privados, também os procedimentos e os valores pagos podem ser definidos por prestadores privados.

Então, a Baixada [Cuiabana] tem muitos serviços privados. Você acaba sendo refém mesmo do setor privado, não tem como, entendeu?... Por exemplo, teve uma época que a mamografia era ofertada por um [único] prestador. Quer dizer: se ele te cobrar o dobro do que vale, você tem que pagar, porque você tem um compromisso de atender a sua população (E4).

Tem mais serviços privados do que públicos..., o estado tem investido pouco em serviços públicos... (E5).

Historicamente, o Estado brasileiro tende a fomentar o crescimento da rede privada de serviços de saúde, em detrimento de investir na ampliação de sua rede própria, o que já era apontado por Braga e Paula (1981), quando informam que, desde 1945, a rede particular era superior à rede oficial pública. Tal tendência se mantém, conforme os achados de Souza et al. (2014), que mostram a maioria $(73,4 \%)$ dos estabelecimentos de saúde situados na rede privada, observando, ainda, uma elevada proporção de oferta de serviços ao SUS por meio de instituições de natureza privada. Se, nos anos 1960 e 70, o Estado já sustentava uma demanda relacionada a uma área de acumulação de capital formada pela rede privada prestadora de serviços médicos, pela indústria farmacêutica e de 
equipamentos médicos (BRAGA; PAULA, 1981), a perpetuação desse cenário (SOUZA et al., 2014) corrobora a análise feita por aqueles autores.

De acordo com Braga e Paula (1981, p.109) "a propriedade privada lucrativa de unidades de serviços de saúde ocupa posição de destaque no Brasil”. Após a unificação dos institutos de assistência previdenciária, aumentaram a importância, influência e dimensão dos mesmos. Nesse contexto, instala-se a hegemonia da medicina previdenciária no país, que se expande mediante seu apoio às unidades privadas. "E se foi esse o caminho seguido, isto decorreu exatamente da constituição prévia dos interesses empresariais, capazes de moldar a parte fundamental da política de saúde adotada desde então [...]" (BRAGA; PAULA, p.109-110). A análise feita por esses autores pode fundamentar as explicaçôes para a manutenção atual dessa tendência: a ampliação de serviços de saúde privados em detrimento dos serviços públicos.

Os interesses empresariais e capitalistas, como sinalizados por Braga e Paula (1981), ao se espraiarem para o âmbito público, poderiam direcionar os (des) caminhos do SUS. E não se pode descartar a possibilidade de articulação de interesses entre os setores público e privado, pois, como salienta Cohn (2011), a participação do privado no SUS garante-lhe um padrão de rentabilidade e sustentabilidade, ao mesmo tempo significa poupança de investimentos por parte do setor público.

$\mathrm{O}$ processo de credenciamento/habilitação, além do que normatiza o PDR, segue os parâmetros definidos pela Portaria no 1.101 (BRASIL, 2002). Essa portaria é referência na orientação de gestores do SUS dos três níveis de governo no planejamento, na programação e priorização das ações de saúde a serem desenvolvidas, podendo sofrer adequações locorregionais, de acordo com a realidade epidemiológica e financeira (BRASIL, 2002).

A portaria é utilizada na SES e nas Comissões Intergestores Bipartites (CIB) e Regionais (CIR) para fornecimento de parâmetros de cobertura assistencial no âmbito do SUS, subsidiando a PPI e a análise de cobertura no estado de MT. No entanto, a percepção dos técnicos da SES é de que esse documento não atende às necessidades de saúde da população, estando abaixo do que a realidade locorregional carece.

Os critérios [de cobertura assistencial] são baseados na parametrização da Portaria 1.101(...), que já estão desatualizados (E1). 
Na PPI, os parâmetros definidos pelo Ministério da Saúde na Portaria 1.101 já não

atendem à nossa realidade, estão abaixo do que precisamos (E5).

No entanto, ressalta-se a necessidade de se relativizar a importância dos parâmetros de cobertura da Portaria GM no 1.101, porque

Eles instituem uma referência para avaliar carências e excessos, mas não devem ser tomados como ponto de chegada, [...] a ser atingido quanto à oferta de consultas especializadas. É possível que a própria implantação dos protocolos assistenciais reduza as demandas por consultas em algumas especialidades a ponto de forçar, inclusive, a própria atualização de seus parâmetros de cobertura específicos. A confirmação ou não dessa possibilidade é uma questão em aberto, uma vez que a construção dos parâmetros de cobertura não se deu no contexto de padronização de condutas para enfrentamento de quadros clínicos (MACHADO, 2006, p.85).

Os credenciamentos e as habilitaçôes dos serviços de saúde deveriam ser compatíveis com as necessidades regionais expressas no PDR. No entanto, constata-se que o PDR vigente data de 2005 e, ainda assim, é apenas uma atualização daquele de 2001.

Além disso, o TCU (BRASIL, 2009) identificou que o estado de MT encontra-se com a PPI desatualizada em seu aspecto físico, sendo atualizada apenas quanto ao aspecto financeiro. Nesse caso, a PPI no estado, além de não utilizar parâmetros que atendam à realidade locorregional,

[...] torna-se apenas um instrumento de distribuição de recursos, pois não há condições de administrar de forma efetiva as cotas físicas tanto dos municípios que executam as açôes, como daqueles que referenciam sua demanda para os polos de atendimento (BRASIL, 2009, p.8).

Contribuindo para tais prejuízos no planejamento e controle das ações de saúde por parte do estado, existe a desatualização dos dados do CNES e a atuação passiva das CIR na CIB estadual, haja vista que elas somente participam das discussões nessa instância quando o estado as convoca, e, mesmo assim, "essas entidades são omissas quanto ao seu papel de fiscalização da execução do que foi pactuado entre os entes federados", conforme identificado em auditoria do TCU (BRASIL, 2009, p. 9).

A frágil fiscalização por parte das instâncias colegiadas regionais e a desatualização dos instrumentos de planejamento, avaliação e controle das ações de saúde sinalizam a possibilidade de haver sérios prejuízos quanto ao atendimento das necessidades de saúde da população. 
Em relação à formalização dos vínculos com o SUS, as evidências empíricas levantadas apontam que a maioria dos serviços ambulatoriais de média e alta complexidade do estado de MT é credenciada ou conveniada.

Desde a Portaria no 358/GM de 2006, há a instituição do termo "contratação de serviços" para todo e qualquer acordo entre o poder público e o setor privado. Essa Portaria sistematizou os instrumentos que deveriam ser utilizados na contratação: a) o convênio utilizado para parcerias com empresas filantrópicas ou sem fins lucrativos; b) o contrato de gestão com organizações sociais, quando o objeto do contrato for a transferência da gestão de um órgão público para tais organizaçóes; c) o contrato administrativo com empresas privadas com finalidades lucrativas ou quando o objeto for a contratação de serviços prestados pelas organizações sociais (BRASIL, 2006a).

Atualmente, a Portaria no 3.410 (BRASIL, 2013) regulamenta as diretrizes operacionais da contratualização hospitalar no âmbito da Política Nacional de Atenção Hospitalar (PNHOSP) no SUS. A análise dessa portaria é relevante devido ao fato de que a maioria dos hospitais provê, também, atendimento ambulatorial, foco deste estudo. Ela trata da relação entre gestores públicos de saúde e hospitais integrantes do SUS por meio de instrumento formal de contratualização, que estabelece os compromissos entre as partes, assegurando a qualificação da assistência e da gestão hospitalar, de acordo com as diretrizes estabelecidas na PNHOSP.

O processo de contratualização tem como objetivos a definição e pactuação de serviços de saúde, de ensino e pesquisa entre o gestor local de saúde e as unidades hospitalares, deixando claros a alocação e o repasse de recursos financeiros, mediante cumprimento de metas quali-quantitativas, visando à melhoria do processo de gestão e atenção hospitalar e favorecendo o controle social e a transparência (BRASIL, 2013).

$\mathrm{O}$ artigo 24 da Portaria no 3.410 (BRASIL, 2013b), que trata do processo de contratualização das ações e serviços de saúde, define as modalidades que o gestor poderá utilizar nos instrumentos contratuais:

I - Convênio: firmado entre o gestor do SUS com entidades beneficentes sem fins lucrativos [...] e com empresas e fundaçôes públicas;

II - Contrato Administrativo: firmado entre o gestor do SUS e entidades públicas e privadas com ou sem fins lucrativos, quando o objeto de contrato for compra de ações e serviços de saúde [...]; 
III - Contrato de Gestão: firmado entre gestores do SUS e a entidade privada sem fins

lucrativos, qualificada como Organização Social (OS) [...];

IV - Protocolo de Cooperação entre Entes Públicos (PCEP) [...];

V - Termo de Parceria: instrumento firmado entre o gestor do SUS e Organizações da Sociedade Civil de Interesse Público (OSCIP) [...];

VI - Termo de Compromisso ou Contrato de Gestão: firmado entre o gestor do SUS e o hospital sob sua gerência e gestão.

A relação entre os gestores do SUS e os provedores privados deveria ser mediada por instrumento contratual da modalidade de contrato administrativo (exceto quando estabelecimentos filantrópicos) e não em forma de convênios, como referido pelos informantes.

Os contratos devem ser claros quanto às regras que envolvem a relação entre o SUS e os serviços de saúde, buscando uma negociação cooperativa em que ambos tenham "soma positiva" e não uma negociação conflitiva na qual o que uma parte ganha a outra perde, ou o considerado "jogo soma/zero" (MATUS, 1996; HUERTAS, 1996), como o que vem ocorrendo nesse estado, em relação à participação do setor privado no SUS. Algumas falas salientam a falta de transparência quando inexiste o contrato administrativo entre o SUS e os serviços privados/filantrópicos, deixando de ser uma parceria e tornando-se uma relação desequilibrada entre os entes, que gera mais benefícios para o prestador privado.

[...] Assim, até onde eu sei, onde existem os contratos, as regras estão postas. Onde não existe... [pausa da entrevistada, subentendendo ausência de regras] (E4).

[Há necessidade de]... rever esses contratos, né? com os prestadores [privados] pra ter mais qualidade... (E 5)

No que tange aos serviços filantrópicos, atualmente não estão sendo feitas visitas técnicas da Vigilância Sanitária para a emissão do alvará de funcionamento, como ocorria no passado. Atualmente, é feita apenas a análise documental, o que foi determinado pelo gestor estadual de saúde anterior, que, para não disponibilizar recursos na viabilização da visita técnica, encontrou essa forma "mais fácil" para liberar o alvará. $\mathrm{Ou}$, talvez, por facilitar a implementação de serviços que não estivessem nas devidas condições técnicas para seu funcionamento, ferindo o disposto na Lei no 9.782/1999, que define o Sistema Nacional de Vigilância Sanitária e criou a Agência Nacional de Vigilância Sanitária (BRASIL, 1999), e na Portaria Ministerial no 3.410 (BRASIL, 2013). 
[...] porque se eles [técnicos da Visa] forem agora, eles podem cancelar o alvará que eles deram... O secretário anterior não queria mais que as pessoas da vigilância sanitária fossem 'in loco' avaliar, aí algum motivo, né, ele tinha (E2).

A tendência é que se a vigilância não concede o alvará é porque ele [o serviço] tá pendente em alguma coisa, né? (E3).

Em que pese a possibilidade de cooperação e/ou conflito na relação interfederativa entre Anvisa e Visa estaduais (PÓ, 2011), se não estão ocorrendo visitas técnicas para emissão do alvará de funcionamento desses estabelecimentos, questiona-se acerca da fiscalização sanitária prevista na Portaria Ministerial $\mathrm{n}^{\mathrm{o}}$ 3.410/2013. Esta, de competência dos entes subnacionais, deveria ser realizada também mediante visitas in loco regulares, tanto no processo de contratualização dos serviços quanto no monitoramento e na avaliação do cumprimento das metas contratadas.

Ressalta-se que as visitas de que trata essa portaria estão previstas também no Plano Operativo Anual (POA) e deveriam ser realizadas tanto pelos técnicos do Escritório Regional de Saúde quanto pelos da Superintendência de Avaliação e Controle da SES.

\section{Controle e Avaliação da SES}

O convênio com os serviços de saúde é feito pela instância jurídica da SES. É elaborado o POA, no qual devem ser especificados: a caracterização geral em termos de estrutura física, tecnológica e de recursos humanos; as atividades pactuadas e conveniadas; as metas quali-quantitativas; os indicadores do estabelecimento de saúde, referentes à assistência ambulatorial e hospitalar (BRASIL, 2012). O POA detalha o que o estabelecimento possui e o que ele se compromete a ofertar, em relação à média e alta complexidade.

Quando o estabelecimento de saúde começa prestar o serviço acordado, é instituída pelo gestor estadual de saúde uma comissão de avaliação de contratos, que se reúne mensalmente. Essa comissão é publicada em portaria da SES, respondendo ao que preceitua a Portaria no 3.410 (BRASIL, 2013, art.32, $\$ 1^{\circ}$ ), cabendo-lhe monitorar as ações e os serviços de saúde pactuados, devendo:

I - avaliar o cumprimento das metas quali-quantitativas e físico-financeiras;

II - avaliar a capacidade instalada;

III - readequar as metas pactuadas, os recursos financeiros a serem repassados [...] 
A avaliação dos serviços ambulatoriais de média e alta complexidade, relativa

ao cumprimento das metas quali-quantitativas, é feita através do POA - uma das partes do processo de contratualização, segundo o Ministério da Saúde (BRASIL, 2012) - e da Ficha de Programação Orçamentária (FPO).

Como a maioria dos serviços ambulatoriais ou hospitalares é regida por convênios, depois da elaboração do POA, o estabelecimento de saúde é credenciado e o setor de Controle e Avaliação da SES elabora a FPO com base naquele plano. Essa ficha consolida todos os procedimentos que o estabelecimento deverá realizar mensalmente, especificando o procedimento realizado, a quantidade, o valor médio unitário pela tabela SUS, o valor total mensal e o tipo de fundo financeiro do SUS que irá subsidiar tais procedimentos.

Através da FPO, a comissão de avaliação de contratos avalia os relatórios encaminhados pelo estabelecimento de saúde e avalia o que foi ou não executado quanto aos procedimentos. As metas podem ou não ser alcançadas, e mesmo ultrapassadas. Se as metas não são atingidas, reduz-se o valor pago; quando ultrapassadas, o valor é glosado. Nesse caso, a comissão discute com o prestador e altera a FPO para que ele receba o valor dos procedimentos glosados. É a "FPO ativa", ou seja, é flexível de acordo com a situação. Após essa avaliação os relatórios são encaminhados para a Gerência de Sistemas de Informação objetivando o cruzamento das informações com as que constam do CNES/SIA para efetivar o pagamento.

Em um dos POA analisados, observou-se que as metas quantitativas pactuadas representam um parâmetro de $90 \%$ para a remuneração mensal da parcela préfixada, enquanto que as metas qualitativas representam $10 \%$ desse parâmetro. Tal achado remete ao histórico pagamento por quantidade de procedimentos e suas repercussões na qualidade da assistência.

Foram constatadas dificuldades na realização de avaliação e controle dos serviços in loco devido à falta de recursos humanos e cortes de recursos financeiros referentes às diárias para viagens, entre outras limitações. Diante dessa situação, os técnicos da SES tentam, na medida do possível, analisar os relatórios dos estabelecimentos de saúde. E mesmo assim, são constatadas muitas irregularidades, como a realização de procedimentos ambulatoriais sem necessidades, sendo a maioria dos laudos normais. Tal fato, possivelmente, tem como um de seus incentivos a política de pagamento por quantidade de procedimento. 
Impedimentos, por exemplo: são muitas viagens pra poder ir e sempre cortam as diárias, aí você nunca consegue fazer o controle e avaliação. Mas a gente consegue fazer através da análise documental (E3).

Aqui é visto sic o percentual de laudos alterados e os normais. Aí você vê uma quantidade [de laudos] muito normal que não deveria [pausa], entende? Você chega à conclusão que não deveriam ser autorizados, se tivessem olhado o protocolo, de repente, não teria tido necessidade de fazer essa ressonância. $\mathrm{O}$ médico regulador poderia ver isso (E2).

Atualmente, existem duas situaçoôes de avaliação e controle na SES: a dos serviços contratualizados que estão sob a responsabilidade do setor de controle e avaliação e a dos serviços privados/filantrópicos e dos hospitais regionais, administrados pelas Organizações Sociais de Saúde (OSS). Na primeira, a avaliação e o controle são feitos pela Comissão de Avaliação de Contratos. Na segunda, não existe uma comissão instituída formalmente, e a avaliação e o controle não são feitos pelos técnicos do setor de Controle e Avaliação. Esses serviços estão sob a responsabilidade de outra comissão, diretamente ligada ao gestor estadual, e é ela que faz os contratos, bem como avalia e monitora esses serviços. Portanto, o setor de Controle e Avaliação da SES não tem acesso a esses contratos:

[...] hoje nós temos duas situações, os contratualizados, que estão no setor de contratualização, que é da nossa coordenadoria e temos outros, inclusive os [hospitais] regionais, que se transformaram em OSS, que têm outra comissão lá em cima que cuida deles. As de lá de cima, acho que, praticamente, não temos acesso (E3).

Não temos acesso nenhum às OSS (E2).

Segundo os técnicos da SES, as OSS não trabalham com a tabela SUS, recebendo valores muito maiores. Também solicitam exames sem obedecer aos protocolos, aos parâmetros definidos pelo MS, pela CIB e pela central de regulação do estado, a exemplo do exame de ressonância magnética. Esse é um exame de alta complexidade, sobre o qual o estado tem o controle e a responsabilidade. $\mathrm{O}$ parâmetro é o estabelecido pela PPI, e já superior à demanda; apesar disso as OSS "reclamam" desses parâmetros.

Eles recebem uma contrapartida [...], essas OSS não trabalham só com o valor SUS, é duas, três, quatro vezes o valor. Ela recebe o recurso financeiro mais a produção..., ela é encaminhada aqui pra gerência de sistema onde é processada (E3).

[...] a central de regulação da região, ela disse que não precisa disso, 55 é a cota deles para a ressonância magnética e é suficiente pra atender a demanda mensal na parte ambulatorial e as OSS instituíram que é 300 que eles querem. Não fazem nada, estudo, pesquisa, nada, só querem isso e pronto e a preço que eles querem, mas nossa [pausa] tem seus limites, né?(E2). 
As Organizações Sociais (OS) surgem no final dos anos 1990, na Reforma do

Estado promovida no governo de Fernando Henrique Cardoso. Tais instâncias não integram a administração pública, sendo consideradas entes privados, sem fins lucrativos, com finalidade de executar serviços públicos de cunho social sob o controle e o apoio financeiro do setor público. Existem muitas críticas a essa alternativa de modelo jurídico-institucional, que, apesar de não estar integrada à administração pública, executa serviços públicos com recursos, pessoal e bens públicos (PINTO et al., 2014).

A ideologia neoliberal, que marcou a década de 1980 e se projetou para a seguinte, tendo como objetivos principais a desregulação e a liberalização dos mercados nacionais e internacionais, afetou o mercado de trabalho, ocasionando a privatização de empresas estatais e serviços públicos, além da redução significativa do tamanho do Estado e de suas responsabilidades sociais (ALMEIDA, 2012).

$\mathrm{Na}$ saúde brasileira, o crescimento do setor privado vem sendo subsidiado pelo setor público, mediante a contratação ou a terceirização de serviços, efetivada por vários instrumentos, em particular aqueles concebidos no âmbito da reforma de Estado neoliberal. Entre outros exemplos de subsídios para o crescimento do setor privado, salienta-se a terceirização de serviços viabilizada pelas organizações sociais (GLOBEKNER, 2011). Vale a pena destacar que tramitam no STF duas Ações Diretas de Inconstitucionalidade contra a lei de criação de OS (GLOBEKNER, 2011; PINTO et al., 2014).

A lógica da compra de atividades do setor privado pelo setor público, na forma de terceirização, pode ser interpretada como a adoção, por parte da administração pública, de modelos de gestão desenvolvidos pelo setor privado e considerados "mais eficientes e com melhores resultados" (MATHONNAT, 2006; PREKER, 2005). Essa prática foi disseminada durante os últimos trinta anos, com base nos princípios do New Public Management (NPM), que surge de um conjunto de teorias administrativas, representadas pela aplicação da "gerência" sob a ótica empresarial para otimizar o desempenho do setor público. O NPM parece estar ligado a quatro grandes tendências na administração pública nas últimas décadas do século XX: 1) a tentativa de reverter o crescimento da máquina pública; 2) a tendência à privatização, com ênfase no papel secundário da prestação direta de serviços pelo governo; 3) a intensificação do uso de tecnologia da informação; e 4) uma agenda mais 
internacionalizada, com foco nas questôes gerais da administração pública e cooperação intergovernamental (HOOD, 1991; POLLIT, 1990).

Nessa perspectiva neoliberal ou neoconservadora, a provisão do bem estar, originariamente a cargo do Estado de Bem-Estar Social (Welfare State), passa a pertencer ao âmbito privado, por conta do mercado, devendo o Estado intervir apenas quando surge necessidade de "aliviar" a pobreza absoluta e de efetuar serviços que o setor privado não possa ou não queira. Nesse contexto, os direitos sociais e a obrigação da sociedade de garanti-los por meio da ação estatal, assim como a universalidade, igualdade e gratuidade dos serviços sociais, são abolidos. A privatização como elemento central da estratégia neoliberal só interessa na medida em que a administração de fundos e a produção de serviços sejam atividades economicamente rentáveis (SOARES, 2012).

No âmbito do SUS, as terceirizaçôes via OSS e outros novos modelos de gestão ocorrem simultaneamente ao desenvolvimento dos dispositivos legais da União na estruturação desse sistema desde as Normas Operacionais Básicas dos anos 1990 (LEVCOVITZ; LIMA; MACHADO, 2001) até o Pacto pela Saúde de 2006, que consagra o conceito de gestão compartilhada e solidária do SUS (FADEL et al., 2009). Tal processo reflete a ideologia neoliberal do Estado, utilizando, entre outros, os "princípios do NPM" como maneira de tentar "justificar" a redução das responsabilidades do Estado em uma área tão estratégica como a saúde.

Diante do exposto, levantam-se algumas indagações que causam "certa inquietação": por que o estado de Mato Grosso tem interesse em manter tais parcerias com o setor privado em detrimento do investimento em sua rede oficial própria? Por que o gestor estadual do SUS mantém uma comissão diretamente ligada a ele para tratar dos contratos, da avaliação e do monitoramento das OSS, quando já existe um setor específico de Controle e Avaliação da SES destinado a essa finalidade? Por que esse setor não tem acesso àqueles contratos? Por que a adoção dessas formas jurídicas de gestão que mantêm tal relação público-privada no SUS?

\section{Pagamento do setor privado/filantrópico e OSS}

$\mathrm{Na}$ data da divulgação do Pacto pela Saúde, é emitida também a Portaria ${ }^{\circ}$ 358, que institui diretrizes para a contratação de serviços privados no âmbito do SUS, reiterando que "para efeito da remuneração dos serviços deverão ter como referência a Tabela de Procedimentos do SUS” (BRASIL, 2006a). 
Ao utilizar tal tabela como referência e não como limite de pagamento pelos procedimentos, essa portaria "abre brechas" para pagamentos diferenciados nos contratos de gestão com os serviços privados, celebrados por estados e municípios, via OSS, o que pode ocasionar pagamentos superiores aos valores definidos na Tabela do SUS, como referido por técnicos da SES.

O Ministério da Saúde repassa aos municípios ou ao estado o valor da tabela do SUS, segundo a produção apresentada no sistema; porém, os hospitais geridos por OSS recebem um valor muito superior à sua produção, sendo a diferença paga pelo estado de MT.

Depois que os hospitais geridos por OSS passaram a receber valores diferenciados, no estado de MT, os hospitais filantrópicos, que antes trabalhavam dentro dessa tabela, passaram a "cobrar" um valor próximo ao das OSS, com exceção de um, que continua trabalhando dentro do preço SUS, com boa produção.

$\mathrm{O}$ setor de avaliação e controle da SES não tem acesso às negociações de valores acordados com as OSS; os técnicos recebem o contrato ou convênio com o valor final a ser pago, mas, ao calcularem o valor dos procedimentos pela tabela SUS, constatam que o valor negociado entre o gestor estadual e o setor privado é bem superior.

Os técnicos da SES referem que houve uma redução de recursos financeiros de forma "estratégica" para os quatro hospitais regionais do estado, com vistas a facilitar a implantação da gestão por OSS nesses estabelecimentos. É citado o exemplo do hospital regional do município de Cáceres: os técnicos da SES que fizeram a auditoria, mediante visita in loco, avaliaram que o hospital vinha apresentando uma boa produção; porém, houve uma redução progressiva de recursos financeiros para a unidade, no sentido de "pressionar" sua gestão por OSS.

Os nossos [hospitais] regionais trabalhavam bonitinho, aí eles começaram a fazer o que? Diminuía o dinheiro que mandavam pra lá. Foi uma estratégia das pessoas, não mandar o dinheiro pra eles, pra poder eles chegarem a um ponto que eles não aguentaram mais! Aí, o que eles fizeram? Colocaram as OSS hiperfaturando (E2).

A existência de um sistema de saúde híbrido público-privado de prestação de serviços constitui um foco de tensóes permanentes com o consumo de recursos públicos para o financiamento da demanda e de instalaçôes utilizadas pelos provedores privados. Outro foco de conflitos é a disputa entre os prestadores de serviços (médicos, hospitais e unidades de diagnóstico e terapia) pelos valores de remuneração das atividades assistenciais (BAHIA, 2005). 
Os aspectos salientados por Bahia (2005) podem ser observados na realidade do estado de MT quando este provê recursos diferenciados para o funcionamento do setor privado na gestão de serviços públicos na modalidade de OS, com remuneração dos procedimentos bem acima do previsto na tabela do SUS. Questiona-se o seu controle sobre as OSS, haja vista que o setor de Avaliação e Controle da SES não tem acesso aos seus contratos, tampouco os monitora ou avalia.

Soares (2012) explica que é comum nos países latino-americanos haver um processo "seletivo" de privatização, impulsionado por políticas estatais direcionadas a garantir a necessidade de um mercado criando uma demanda destinada aos serviços privados. Isso só ocorre quando os serviços ofertados pelo setor público são vistos como insuficientes e/ou de má qualidade, visando tornar o processo de privatização socialmente aceitável. Tal fato está diretamente vinculado ao corte do gasto social público, visto como causa e não como consequência da crise fiscal do Estado. Esse corte tem um significado deliberado de "desfinanciamento" das instituições públicas, com seu consequente sucateamento e crescente desprestígio.

\section{Considerações finais}

A relação público-privada no âmbito da atenção ambulatorial no estado de MT é complexa e nebulosa. O expressivo número de estabelecimentos privados em detrimento dos reduzidos equivalentes públicos evidenciam essa complexidade e a fragilidade do setor público frente ao privado.

A fragilização do setor público, com a aparente "incompetência de gestão" do estado, constatada pela desatualização de instrumentos de planejamento e dos poucos contratos com o setor privado; a redução da transferência de recursos financeiros, fomentando a criação de modelos de gestão públicoprivada de pouca confiabilidade e transparência, como as OSS, além de outras irregularidades, fomentou a entrada em cena de outros atores na luta pela saúde da população, como o Ministério Público e o TCU. Frequentemente, o controle social e as comissões intergestores têm ficado como coadjuvantes do processo, frente a esses novos atores.

Apesar da legislação do SUS definir elementos essenciais para o alcance de seus princípios, tem permitido "espaços" para que o setor privado se insira e 
seja beneficiado pelo Estado. Somam-se a isso os conflitos de poder político e econômico entre os grupos de interesse na privatização da saúde no Brasil e em MT, conformando grandes obstáculos para a operacionalização do SUS, além de representarem constante e perigoso movimento dialético de forças entre o formal e o real. ${ }^{1}$

\section{Agradecimentos}

Os autores agradecem ao CNPq (Proc. no 481893/2010-5) e à Capes (Procad-NF no 2275/2008), pelo apoio ao projeto em que este trabalho se insere.

\section{Referências}

ALMEIDA, C. Reformas de sistemas de saúde: tendências internacionais, modelos e resultados. In: GIOVANELLA, L. et al. (Org.). Políticas e sistemas de saúde no Brasil. Rio de Janeiro: Fiocruz, 2012. p. 759-801.

BAHIA, L. Padrōes e mudanças no financiamento e regulação do sistema de saúde brasileiro: impactos sobre as relações entre o público e o privado. Saúde e Sociedade, São Paulo, v. 14, n. 2, p. 9-30, 2005.

. A démarche do privado e público no sistema de atenção à saúde no Brasil em tempos de democracia e ajuste fiscal, 1988-2008. In: MATA, G. C.; LIMA, J. C. (Org.). Estado, sociedade e formação profissional em saúde: contradiçôes e desafios em 20 anos de SUS. Rio de Janeiro: Editora Fiocruz/EPSJV, 2008.

BRASIL. Senado Federal. Constituição [da] República Federativa do Brasil. Brasília: Senado Federal, 1988. Disponível em: < http://www.planalto.gov.br/ccivil_03/constituicao/ constituicao.htm> Acesso em: 23 jan.2013

. Lei no 8.080/1990, de 19 de setembro de 1990. Dispõe sobre as condições para a promoção, proteção e recuperação da saúde, a organização e o funcionamento dos serviços correspondentes. Disponível em: <http://portal.saude.gov.br/portal/arquivos/pdf/lei8080. pdf>. Acesso em: 10 fev. 2013.

. Lei n ${ }^{\circ} 9.637$, de 15 de maio de 1998. Dispõe sobre a qualificação de entidades como organizações sociais, a criação do Programa Nacional de Publicização, a extinção dos órgãos e entidades que menciona e a absorção de suas atividades por organizaçôes sociais. Disponível em: <http://www.planalto.gov.br/ccivil_03/leis/19637.htm> Acesso em: 24 fev. 2014.

. Lei no 9.782, de 26 de janeiro de 1999. Define o Sistema Nacional de Vigilância Sanitária e cria a Agência Nacional de Vigilância Sanitária. Disponível em:<http://www. planalto.gov.br/ccivil_03/leis/19782.htm>. Acesso em: 24 fev. 2014 
Ministério da Saúde. Portaria $n^{\circ} 1.101$, de 12 de junho de 2002. Dispõe sobre parâmetros de cobertura assistencial no âmbito do SUS. Brasília-DF, 2002. Disponível em: <http://www.saude.gov.br/sas/PORTARIAS/Port2002/Gm/GM-1101.htm>. Acesso: 30 abr. 2014.

. Portaria no 358, de 22 de fevereiro de 2006. Institui diretrizes para contratação de serviços assistenciais no âmbito do SUS. Brasília: Ministério da Saúde, 2006a. Disponível em: <http://www.saude.gov.br/arquivos/File/CIB/LEGIS/PortGM_358_22_fevereiro_2006. pdf>. Acesso em: 15 abr.2014.

Portaria no 399, de 22 de fevereiro de 2006. Institui o Pacto pela Saúde. Ministério da Saúde, 2006b. Disponível em: <http://pfdc.pgr.mpf.gov.br/atuacao-e-conteudos-deapoio/legislacao/saude/portarias/portaria_MS_399.2006> Acesso em: 10 fev.2013.

Decreto no 7.508, de 28 de junho de 2011. Regulamenta a Lei no 8.080/1990. Disponível em: <http://ww.planalto.gov.br/ccivil_03/_ato2011-2014/2011/decreto/D7508. htm>. Acesso em: 12 fev. 2013

Portaria no 3.410 , de 30 de dezembro de 2013. Estabelece as diretrizes para a contratualização de hospitais no âmbito do SUS em consonância com a Política Nacional de Atenção Hospitalar. Disponível em:<http://ww.bvsms.saude.gov.br/bvs/saudelegis/ gm/2014/prt3410_30_12_2013.html> Acesso em: 20 fev.2014.

. Tribunal de Contas da União. Relatório de auditoria. Grupo I; Classe V - Plenário. TC 014.801/2009-7.

BARDIN, L. Análise de Conteúdo. São Paulo: Martins Fontes, 1977.

BRAGA, J. C.; PAULA, S. G. Saúde e previdência: estudos de política social. São Paulo: Cebes-Hucitec, 1981.

CAMPOS, G. W. Políticas sociais: o público e o privado na saúde brasileira. Le Monde Diplomatique, mar. 2008, p.28-29. Disponível em: <http://diplomatique.uol.com.br/ artigo >. Acesso em: 19 abr. 2011

COHN, A. Questionando conceitos: o público e o privado na saúde no século 21. In: SANTOS, N.; AMARANTE, P. D. (Org.). Gestão pública e relação público-privado na saúde. Rio de Janeiro: Cebes, 2011. p. 244-251.

FADEL, C. B. et al. Administração pública: o pacto pela saúde como uma nova estratégia de racionalização das ações e serviços em saúde no Brasil. Rev. de Administração Pública, Rio de Janeiro, v. 43, n. 2, p. 445-456, 2009.

GLOBEKNER, O. A. A saúde entre o público e o privado: o desafio da alocação social dos recursos sanitários escassos. Curitiba: Juruá, 2011. 
GUIMARÃES, L. Política de saúde em Mato Grosso: dois mandatos para a construção da regionalização. In: NETO MÜLLER, J. S.; SOARES, N. R.; SCHRADER, F. T. (Org.). Políticas de saúde em Mato Grosso: participação social, descentralização e regionalização. Cuiabá: EdUFMT, 2012. p.123- 152.

HOOD, C. A Public Management for all Seasons? Public Admi., v. 69, n. 1, p. 3-19, 1991.

HUERTAS, F. O método PES: entrevista com Matus. São Paulo: FUNDAP, 1996.

LEVCOVITZ, E.; LIMA, L. D.; MACHADO, C. V. Política de saúde nos anos 90: relações intergovernamentais e o papel das Normas Operacionais Básicas. Ciência \& Saúde Coletiva, v. 6, n. 2, p. 269-291, 2001.

MACHADO, J. A. Mapa para Implantação de Protocolos Assistenciais: necessidades, diretrizes e orientações gerais: relatório final. Relatório. Brasília, 2006.

MATHONNAT, J. Contracting is not an end in itself. B World Health Organ, v. 84, n. 11, p. 912-913, 2006.

MENICUCCI, T. G. A reforma sanitária brasileira e as relações entre o público e o privado. In: SANTOS, N. R.; AMARANTE, P. D. (Org.). Gestão pública e relação público-privada na saúde. Rio de Janeiro: Cebes, 2010. p. 180-197.

MATUS, C. O método PES: roteiro de análise teórica. São Paulo: FUNDAP, 1996.

PAIM. J. S. O que é o SUS. Rio de Janeiro: Fiocruz, 2009.

PINTO, I. C. M. et al. Organização do SUS e diferentes modalidades de gestão e gerenciamento dos serviços e recursos públicos de saúde. In: PAIM, J.S.; ALMEIDA-FILHO, N. (Org.). Saúde coletiva: teoria e prática. Rio de Janeiro: MedBook, 2014. p. 231-243.

PÓ, M. V. Institucionalidade e desafios da regulação na área de saúde no Brasil. In: SANTOS, N. R.; AMARANTE, P. D. (Org.). Gestão pública e relação público-privado na saúde. Rio de Janeiro: Cebes, 2011. p.220-243.

POLLIT, C. H. Managerialism and the public services: the Anglo-American experience. Oxford: Blackwell, 1990.

PREKER, A. S. Managing scarcity through strategic purchasing of health care. In: PREKER, A. S; LANGENBRUNNER, J. C. (Org.) Spending wisely: buying health services for the poor. Washington D.C.: The World Bank, 2005.

ROMANO, C. M. C.; SCATENA, J. H. G. A relação público-privada no SUS: um olhar sobre a assistência ambulatorial de média e alta complexidade na região de saúde da Baixada Cuiabana em MT. Rev. de Administração Pública, Rio de Janeiro, v. 48, n. 2, p. 439-458, mar./abr. 2014. 
SOARES, L. T. Políticas sociais na América Latina. In: GIOVANELLA, L. et al. (Org.). Políticas e sistemas de saúde no Brasil. Rio de Janeiro: Fiocruz, 2012. p. 803-821. SOUZA, L. E. P. et al. Infraestrutura tecnológica do SUS: rede de estabelecimentos, equipamentos, desenvolvimento científico-tecnológico e inovação. In: PAIM, J. S.; ALMEIDA-FILHO, N. (Org.). Saúde coletiva: teoria e prática. Rio de Janeiro: MedBook, 2014. p. 211-229.

\section{Nota}

${ }^{1}$ C. M. C. Romano participou da coleta e processamento dos dados que originaram este trabalho; concepção do presente recorte; seleção e discussão dos dados e redação e revisão do artigo. J. H. G. Scatena e R. T. Kehrig foram responsáveis pela concepção, seleção e discussão dos dados e redação e revisão do artigo. 


\section{Abstract}

Public-private link in the ambulatory care of high and medium complexity within the SUS: the role of the State Health Department of Mato Grosso, Brazil

The origin of the public-private relationship in the health system lays on the creation and development of social welfare. Within the SUS, such relationship is maintained and has gained strength and stability, especially in the levels where there is opportunity for profit. This study, of qualitative basis and focused on the State Health Secretariat (SHS) of Mato Grosso, Brazil, aims to explore, in this management sphere, the public-private link within the ambulatory care of high and medium complexity. Data collection included documents and interviews with technicians from that area and empirical material explored through content analysis. The results showed that: the state accredits/enables or hire ambulatory care services of high and medium complexity according to the logic of private offer; health management is poor; the performance of Regional Inter-Management Commissions is passive; Social Health Organizations have different evaluation and control processes and receive values above SUS standards, not meeting established protocols and parameters. There is no evidence that favouritism towards the private sector will be reversed in the current work of the SHS, on this level of care.

Key words: Unified Health System; health services; ambulatory care. 